\title{
Meal size and feeding rate of the shallow-water lysianassid Anonyx sarsi (Crustacea: Amphipoda)
}

\author{
Bernard Sainte-Marie* \\ Department of Fisheries and Oceans, Arctic Biological Station, 555 boul. Saint-Pierre, Sainte-Anne de Bellevue, Québec \\ H9X 3R4, Canada
}

\begin{abstract}
Mature or almost mature Anonyx sarsi Steele \& Brunel from the Saint Lawrence Estuary and Gulf were held singly and deprived of food for up to $30 \mathrm{~d}$ to measure the effect of starvation on feeding response. After a fixed period of starvation, individuals were fed pieces of freeze-dried squid mantle to determine meal size, feeding rate, and satiation time. Average meal size increased steadily, while egestion decreased, over the first $15 d$ of starvation. The quantity of dry squid ingested after 15 to $30 \mathrm{~d}$ of starvation was constant and followed a normal distribution. On average, males (mean body length $=21.7 \mathrm{~mm}$ ) starved 15 to $30 \mathrm{~d}$ ate 8.9 to $9.1 \mathrm{mg}$ (19 to $22 \%$ of net dry body weight). Average meal size of females apparently decreased with increasing sexual maturity: immature Estuary females (mean body length $=20.9 \mathrm{~mm}$ ) starved 15 to $30 \mathrm{~d}$ ate $7.6 \mathrm{mg}(13 \%$ of net dry body weight), while mature Gulf females (mean body length $=22.4 \mathrm{~mm})$ ate $7.5 \mathrm{mg}(10 \%$ of net dry body weight). The large ovaries were responsible for smaller absolute and relative meal size of females compared to males. Maximum meal size reached 16.1 to $16.4 \mathrm{mg}$ (29 to $37 \%$ of net dry body weight) in females and males, equivalent to $0.1 \mathrm{~g}$ of fresh squid. Meal size was positively correlated with body length and with time spent feeding. Average feeding rates of females $\left(0.9\right.$ to $1.3 \mathrm{mg}$ dry weight min $\left.{ }^{-1}\right)$ and males $(0.5$ to $1.2 \mathrm{mg}$ dry weight $\mathrm{min}^{-1}$ ) starved 15 to $30 \mathrm{~d}$ were similar Feeding rate was not correlated with the duration of starvation.
\end{abstract}

\section{INTRODUCTION}

Lysianassid amphipods represent an important component of the fauna of bathyal, abyssal and highlatitude marine benthos (e.g. Bregazzi 1972, Dayton \& Hessler 1972, Hessler et al. 1978, Dahl 1979, Thurston 1979, Sainte-Marie 1986a, Slattery \& Oliver 1986). Many lysianassid species are known for their carrionfeeding habit, and are presumably attracted to bait from vast areas of bottom (Ingram \& Hessler 1983, Rowe et al, 1986, Sainte-Marie 1986c, Sainte-Marie \& Hargrave 1987).

Carrion is apparently a scarce resource in most marine environments (Rowe \& Staresinic 1979, Stockton \& DeLaca 1982, Smith 1985, Sainte-Marie 1986b) Nonetheless, in high-latitude seas during the winter, and in the deep sea year-round, it may be an important source of nutrients (Amaud 1970, 1977, Rowe \& Staresinic 1979, Stockton \& DeLaca 1982). How lysianassids exploit this ephemeral, temporally and

\footnotetext{
- Present address: Institut Maurice-Lamontagne, Service des Sciences, Pêches et Océans, 850 Route de la Mer, Mont-Joli, Québec G5H 3Z4, Canada
}

spatially unpredictable resource is not fully understood. Empirical and theoretical evidence for contrasting active or passive foraging strategies exists (SainteMarie \& Hargrave 1987). Whatever the strategy for locating carrion, lysianassids may be able to sustain long periods without food, by a combination of gluttonous feeding when carrion is present, long gut retention times, of high assimilation efficiency, and low metabolic rates (Dahl 1979, Smith \& Baldwin 1982, Hargrave 1985, Sainte-Marie 1986a).

While morphological studies have demonstrated the great storage potential of the alimentary tract of some lysianassids (Shulenberger \& Hessler 1974, Dahl 1979, Sainte-Marie 1984), few studies have quantified gut capacities. Present \& Smith (1981) used oven-dried squid mantle to estimate quantities of food ingested over $24 \mathrm{~h}$ by the shallow-water Orchomene limodes Meador \& Present, and found that individuals could ingest a quantity of food representing between 26 and $92 \%$ of their dry body weight in several meals. However, given the generally short residence times of carrion in most shallow and deep marine environments (Stockton \& DeLaca 1982, Sainte-Marie 1986b, c), and the consequent unlikelihood of repeat-feeding, meal 
size is a more appropriate representation of the ingestion capacity of individuals. Hargrave (1985) used timelapse photography to indirectly estimate meal size of the abyssal Eurythenes gryllus (Lichtenstein), by observing contact time of individuals with bait and the concomitant decrease of bait volume. Individuals ingested on average $2.9 \mathrm{~g}$ fresh weight of bait, which represented between 30 and $60 \%$ of their fresh body weight, in one 30 min meal.

Here, I consider the effect of starvation on meal size of the infralittoral, cold-water lysianassid Anonyx sarsi Steele \& Brunel, a primarily carnivorous species (Sainte-Marie \& Lamarche 1985, Sainte-Marie 1986b). Freeze-dried (lyophilized) squid mantle was deemed the most appropriate food type for feeding experiments. It was found that food consumption increased gradually during the first $15 \mathrm{~d}$ of starvation. Thereafter. meal size of healthy individuals remained constant.

\section{MATERIALS AND METHODS}

Collection and maintenance. Anonyx sarsi were collected in early November 1986 from Baie des Rochers (Lat. $47^{\circ} 57^{\prime} 30^{\prime \prime} \mathrm{N}_{i}$ Long, $69^{\circ} 48^{\prime} 30^{\prime \prime} \mathrm{W}$ ) on the north shore of the Middle St. Lawrence Estuary, Canada. Individuals were captured with baited traps deployed for less than $1 \mathrm{~h}$ at low tide. Bait consisted of squid Illex illecebrosus (LeSueur). Specimens were carried back to the Arctic Biological Station in a cooler and transferred within $12 \mathrm{~h}$ of capture into a $65 \mathrm{l}$ tank with circulating, aerated, filtered seawater (Instant Ocean) cooled to $2{ }^{\circ} \mathrm{C}$.

Excess food, consisting of squid mantle stripped of all membranes, was provided during the first $4 \mathrm{~d}$ of captivity. Subsequently, collectively-held amphipods were starved for 5 consecutive $d$ and then given excess food for $1 \mathrm{~d}$. Then, 182 randomly-chosen individuals belonging to the second year class (Anonyx sarsi is a biennial species with 2 discrete size cohorts) were transferred to holders for experimentation. A holder consisted of 2 encasing plastic trays, each comprising 14 alveoli of $25 \mathrm{ml}$. One lysianassid was placed in each alveolus. Alveoli in the top tray opened into the matching bottom tray through a $2 \mathrm{~mm}$ Nytex screen, so faecal material was generally evacuated from the containment alveoli and collected. It was thus possible to keep a record of individual faecal production, while minimizing the occurrence of coprophagy. The top tray was covered with a piece of Plexiglas to prevent the amphipods from escaping, and the holder was immersed in a shallow tank of running seawater Therefore, accumulation of dissolved metabolic wastes (e.g. ammonia) was unlikely

Experimental procedure. Anonyx sarsi were main- tained in holders, without food, for periods of $1,2,3,4$, $5,6,8,10,15,20,25$ and $30 \mathrm{~d}$ following isolation. Holders were checked at least daily to remove dead specimens, moults, and accumulated faecal material. Dead specimens were immediately frozen at $-20^{\circ} \mathrm{C}$ and freeze-dried for dry weight determination. In 8 of the 13 experimental holders, accumulated faecal pellets were counted daily.

Food for experiments was prepared from squid mantle stripped of all membranes. The mantle was cut into small pieces and freeze-dried to constant weight (24 h); pieces ranged in size from 26 to $115 \mathrm{mg}$ dry weight. Squid mantle is suitable for feeding experiments, since it does not break up during soaking, due to its nonfibrous texture (Present \& Smith 1981). Freeze-drying offers an advantage over oven-drying because the flesh is uncooked, its structural and volumetric properties are better preserved (no hardening or shrinking), and small pieces rehydrate within minutes of exposure to water. Oven-drying produces a dense food, with no equivalent in nature, which may overestimate ingestion. Freeze-dried squid was stored for subsequent use at $-20^{\circ} \mathrm{C}$ in individual, air-tight glass vials. After storage for $1 \mathrm{mo}$, a few pieces were freeze-dried for an additional $24 \mathrm{~h}$ and re-weighed. New weight measurements were within $\pm 0.05 \mathrm{mg}$ of original measurements.

To determine meal size, the experimental holder was withdrawn from the water and a piece of squid was introduced into each alveolus. A tray with a $2 \mathrm{~mm}$ Nytex bottom was stacked over the experimental holder, in place of the Plexiglas cover, to ensure that the buoyant pieces of freeze-dried squid were completely underwater during experimentation. Following these manipulations, which required $<1 \mathrm{~min}$, the experimental holder was immersed for precisely $60 \mathrm{~min}$. The choice of an appropriate time period for evaluating meal size is important and should depend on preliminary observations of feeding behaviour Field observations indicated that Anonyx sarsi satiated in 10 to 15 min (Sainte-Marie 1986c). The period must be constant, long enough for animals to satiate, but sufficientiy short so that they do not metabolize and egest part or all of their meal and, possibly, feed anew. These conditions were met in my experiments, since all but one individual became satiated within the first $30 \mathrm{~min}$. and only 3 returned to food after satiating.

Emersion of lysianassids just prior to experimentation may have constituted a shock, but, in my experience, it did not affect their feeding behaviour. This procedure ensured that all individuals were simultaneously exposed to odour stimuli from food and allowed to feed for exactly the same period. Every minute during incubation with squid, individuals were checked to see if they were feeding. Feeding individu- 
als, in contrast to those resting or crawling on the pieces of squid, conspicuously pressed their mouthpieces against the squid surface. After the 60 min feeding period was completed, the experimental holder was removed from the water. Remaining squid was promptly transferred to individual vials, frozen at $-20^{\circ} \mathrm{C}$, and freeze-dried for dry weight determination. Lysianassids were immediately anaesthetized with carbonated water, sexed, measured from tip of cephalon to end of telson, rinsed in distilled water, frozen $\left(-20^{\circ} \mathrm{C}\right)$, and freeze-dried for gross dry weight determination. Measurements of dry weights were made to the nearest $10^{-3} \mathrm{mg}$ on a Cahn 28 electrobalance, but were rounded to the nearest $10^{-2} \mathrm{mg}$ for calculations.

Experiments were routinely started between 1130 and $1300 \mathrm{~h}$. Since Anonyx sarsi is less active in bright light than in darkness (Sainte-Marie 1986b, c), light intensity during experiments was kept low: $6 \mu \mathrm{E} \mathrm{m}^{-2} \mathrm{~s}^{-1}$ above experimental trays, which reduced to $5.5, \mu \mathrm{E} \mathrm{m}^{-2}$ $\mathrm{s}^{-1}$ in alveoli. Endogenous rhythms may also affect feeding behaviour, so one experiment was conducted at $2200 \mathrm{~h}$ to check for day-night effects on meal size. At this time of night, A. sarsi remaining in the $65 \mathrm{l}$ tank were very active, swimming rapidly around the tank's inner wall. One group of 14 individuals, starved for $8 \mathrm{~d}$ concurrently with the experimental group used in the day, was given food according to the above protocol. However, the experiment was conducted in darkness, so time spent feeding on squid was not recorded.

The weight of pieces of freeze-dried squid may change, independently of lysianassid activity, because of diffusion, manipulations, or salt loading (Present \& Smith 1981). Hence, for each of the 2 squid mantles used as food for experiments, a control experiment was performed to obtain correction factors accounting for changes in bait weight. The control procedure was identical to the experimental procedure described above, except that no lysianassids were present in alveoli. Dry weights of squid pieces, before and after the $60 \mathrm{~min}$ immersion, were regressed to obtain a correction factor. The predictive regressions (Table 1) were highly significant and did not differ $(p>0.05)$ in slope or in Y-intercept. Exposure to seawater decreased the weight of freeze-dried squid pieces. Significant predictive regressions were also obtained for blotted fresh weight and freeze-dried weight, and for blotted fresh weight and volume (Table 1). These predictive regressions were used to estimate the fresh weight and volume of a meal.

Absolute meal size was calculated as the difference between initial dry weight of squid, following correction, and final dry weight. Net dry weight of each amphipod was determined by subtracting absolute meal size from gross dry body weight. Relative meal size was the ratio of absolute meal size to net dry weight of amphipod, expressed as a percentage. The feeding rate was calculated by dividing meal size by time spent feeding.

Association between variables was measured using partial correlation, which determines the correlation between pairs of variables when other specified variables are held constant (Sokal \& Rohlf 1981). Linear regression analysis was used to quantifity relations of specific interest. Model II regression (geometric mean regression) was used to describe the functional relation between variables subject to natural variability and measurement error (Ricker 1973). Model I regression (least square regression of $Y$ on $X$ ) was used for predictive purposes (Sokal \& Rohlf 1981).

In most cases, the proposed method of determining meal size should prove to be very accurate. However, a potentially important source of error arises when an amphipod rapidly ingests a large portion of the meal offered during the first minutes of incubation. Before it is ingested, this portion of squid loses much less weight than is predicted by correction factors, because it is only exposed briefly to seawater. Therefore, meal size is underestimated. The magnitude of this error term will depend on meal size, time spent feeding and on how soon lysianassids begin to feed, but it does not exceed 8 to $10 \%$ of absolute meal size.

\section{RESULTS}

Females accounted for $81.3 \%$ of experimental amphipods. All females and most males were immature at the beginning of the experiment: females had nonsetiferous oostegites and males had short antennal flagella. Initially, 2 males were mature, as was clear from their elongate antennal flagella bearing calceoli, enlarged eyes, and silver sperm strands visible through the cuticle. During the course of the experiment, 11 other males became sexually mature, some apparently without moulting. Virtually all females had large, nearly ripe ovaries, visible under the stereomicroscope at $6 \times$ as dark purple or pink convoluted tubes. Oocytes were separated by thin white connective tissue, and could be counted even through the cuticle. Only one female developed setiferous oostegites following a moult on the 21st day of starvation, but by Day 30, at which time she was sacrificed, her ripe eggs had not yet been laid.

During the experiment, several starving Anonyx sarsi moulted, mainly 5 to $6 \mathrm{~d}$ before full moon until $2 \mathrm{~d}$ after. The maximum moult frequency, $28.6 \%$ of 14 individuals, occurred in the group of individuals starved for $25 \mathrm{~d}$. Overall, $17.6 \%$ of males and $3.2 \%$ of females moulted once during the experiment. It seems unlikely that more individuals moulted, but were 
Table 1. Squid mantle. Predictive regressions of volume (V, ml) and dry weight (DW, g) on fresh weight (FW, g), and of dry weight after 60 min immersion in seawater (DW60, mg) on dry weight before immersion (DWO, mg). n: sampie size; $r^{2}$ : coefficient of determination; F: F-ratio of the regression. Regressions coefficients are highly significant $(p<0.001)$

\begin{tabular}{rrrr|}
\hline Equation of regression & $\mathrm{n}$ & $\mathrm{r}^{2}$ & $\mathrm{~F}$ \\
$\mathrm{~V}=0.975 \mathrm{FW}+0.002$ & 19 & 0.996 & 4363.2 \\
$\mathrm{DW}=0.182 \mathrm{FW}-0.004$ & 19 & 0.994 & 3325.4 \\
Squid \# 1: DW60 $=0.948$ DWo -1.473 & 16 & 0.996 & 4501.4 \\
Squid \# 2: DW60 $=0.941$ DWo -1.396 & 15 & 0.996 & 3394.4 \\
\hline
\end{tabular}

unnoticed because they consumed their casts, since $A$. sarsi were never observed to eat an ecdysis. Individuals remained very soft and did not feed, in these and other experiments, for approximately $2 \mathrm{~d}$ after moulting.

In the $25 \mathrm{~d}$ experimental tray, one female and one male died, and 4 other males and one female were obviously diseased and/or severely mutilated. The disease, named 'limb rot' for lack of a specific name, involved the degeneration of appendages, mostly antennae and pereopods, and to a lesser extent pleopods. Mutilated individuals, all recently moulted males, lacked both pairs of antennae and part of the cephalon, which were apparently lost during the moult. This handicap was, in 2 cases, compounded by limb rot. Since antennae are the probable sites involved in odour detection (Dahl 1979, Meador 1981), diseased and mutilated individuals may have been unaware of food. Therefore, I have omitted them, along with individuals which moulted during the $2 \mathrm{~d}$ that preceded feeding, from calculations of average meal size, feeding rate and satiation time (Fig. 1). Overall, mortality was low (2.2\% of 182 individuals): single individuals died after $12,15,17$ and $22 \mathrm{~d}$ of starvation. These were emaciated, and one was heavily parasitized by choniostomatid copepods.

Individuals used in experiments were between 16 and $25 \mathrm{~mm}$ in length. Males were lighter than females, as can be seen by the following functional (F) and predictive (P) regression equations:

$$
\begin{aligned}
& \text { Females }(F): \operatorname{lnBW}=3.69 \operatorname{lnBL}-7.06 ; \mathrm{I}=0.74 \\
& \text { (P): } \ln B W=2.74 \ln B L-4.18 ; r^{2}=0.55 \text {, } \\
& \mathrm{F}=179, \mathrm{p}<0.001, \mathrm{n}=148 \\
& \text { (P): } \ln B W=1.62 \ln B L-1.03 ; r^{2}=0.32 \text {, } \\
& F=15, p<0.001, n=34
\end{aligned}
$$

where $\mathrm{BW}=$ net dry body weight $(\mathrm{mg}) ; \mathrm{BL}=$ body length ( $\mathrm{mm})$. There was a positive but non-significant partial correlation between body length of females and duration of starvation, while a significant positive partial correlation was observed for males (Table 2), probably due to the greater moult frequency.

Faeces production was low $10.3 \pm 0.5$ faecal pellets per individual) on the first day of starvation. Peak egestion occurred on the second $(3.2 \pm 2.5$ faecal pellets per individual) and third day $(3.2 \pm 2.1$ faecal pellets per individual) of starvation, and then decreased steadily for $15 \mathrm{~d}$, at which time egestion ceased. Minimum gut clearance time of individuals starved $>15 \mathrm{~d}$ was $4 \mathrm{~d}$. During the first 6 to $8 \mathrm{~d}$ of starvation, faecal pellets were discrete entities. On Days 2 and 3 , faecal pellets were fragile strands up to 3 to $5 \mathrm{~mm}$ in length, and were larger than pellets produced later. After 8 d of starvation, faecal material was poorly cohesive, appearing as loose aggregates, so stringent enumeration was not possible. For these reasons, counting of faecal pellets is probably, at best, only a fair quantitative indicator of egestion of Anonyx sarsi.

All of the faeces $<2 \mathrm{~mm}$ in length, and most of the larger faeces, passed through the mesh bottom of the containment alveoli. Apparently, coprophagy did not occur, at least during the first $5 \mathrm{~d}$ of starvation, when intensive observations of the amphipods were performed. Fore- and midguts of individuals starved $<10$ d contained varying amounts of more or less digested squid, while guts of individuals starved $\geq 15 \mathrm{~d}$ were empty, or contained a diffuse brownish liquid.

Most 'hungry' individuals attacked squid within 5 min of its introduction into the experimental holder. Those that did not react within this time seemed to ignore it completely for the duration of the experiment, either crawling about the alveoli or resting. Generally, individuals did not remain on food if they were not feeding. However, some did hang motionless on food or crawl slowly about its surface, and it was necessary to scrutinize them to determine if they were feeding or not. Maximum time spent feeding by one individual was $55 \mathrm{~min}$. Such a lengthy period of time was aberrant, since all other individuals fed for 29 min or less (Fig. 1). Feeding sprees were often interspersed with one or two 1 to 2 min resting periods, during which individuals generally clung to food. All but 3 individuals fed only during the first $30 \mathrm{~min}$ of squid exposure. While feecting on bait, very few individuals produced faeces.

Given the opportunity to feed after 6 or fewer d of 


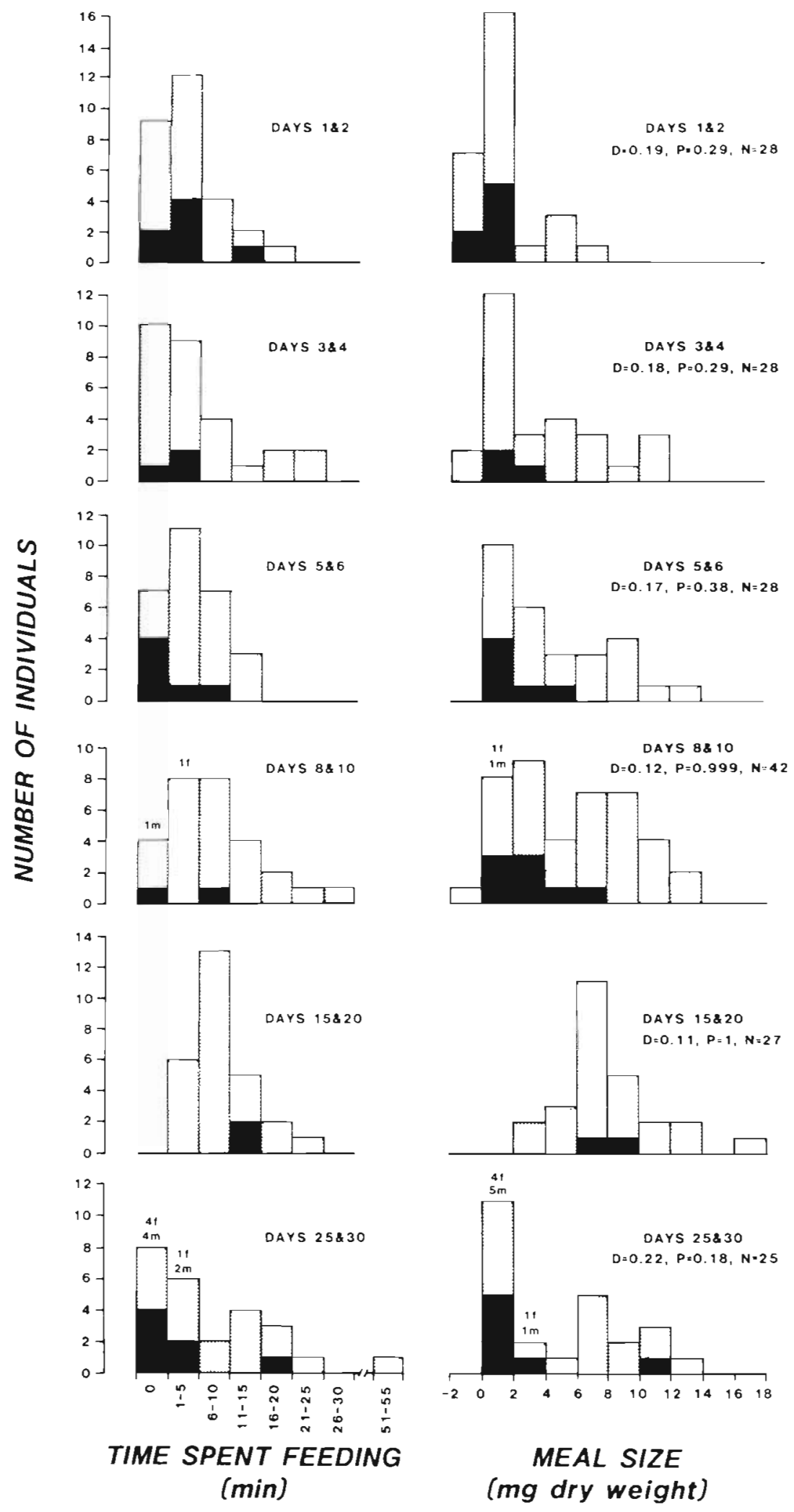

Fig. 1. Anonyx sarsi from Baie des Rochers. Histograms of time spent feeding and of absolute meal size of females (stippled columns) and males (black) starved 1 to $30 \mathrm{~d}$. Frequency distributions of meal size did not differ significantly from a hypothesized normal distribution, according to a Kolmogorov-Smirnov goodness-of-fit test (D statistic and probability level indicated). Numbers and letters (f: females; $\mathrm{m}$ : males) above bars designate diseased and recently-moulted individuals which were excluded from further analyses of data 
Table 2. Anonyx sarsi from Baie des Rochers. Partial correlations between body length (BL), net dry body weight (BW), time spent feeding $(T)$, absolute meal size (M), and duration of starvation (S) for females and males used in feeding experiments. $n$ : sample size

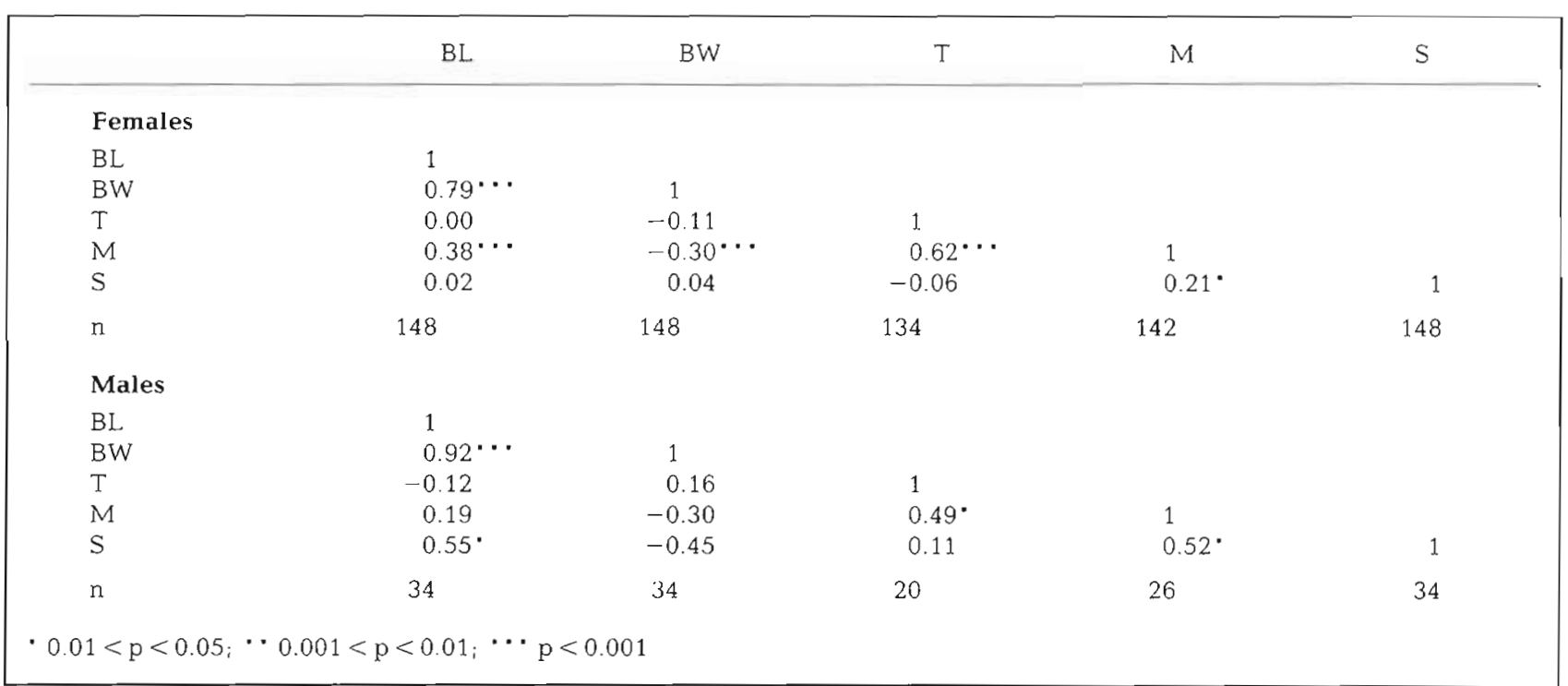

starvation, $\geq 25 \%$ of individuals apparently did not feed, and at least another $25 \%$ spent fewer than 5 min feeding (Fig, 1). This was reflected in the small quantities of squid ingested, generally $<2 \mathrm{mg}$ dry weight (Fig. 1). However, a few specimens fed profusely and skewed to the right the frequency distribution of the quantity of squid ingested per individual. None of these distributions differed significantly from a normal (Gaussian) distribution, according to a KolmogorovSmirnov goodness-of-fit test. After 8 to $20 \mathrm{~d}$ of starvation, most individuals fed more than $5 \mathrm{~min}$, and the distribution of quantities of food ingested conformed almost perfectly to a normal distribution (Fig. 1).

After 25 and $30 \mathrm{~d}$ of starvation, there was a clear dichotomy in the feeding response of individuals. Several individuals did not feed, while the others fed for more than $5 \mathrm{~min}$. This divergence in the feeding pattern was evident in the distribution of quantities of squid ingested (Fig. 1). This change in feeding response was probably due to disease or unsuccesstul moulting which affected individuals in the $25 \mathrm{~d}$ experimental tray.

Females starved for $8 \mathrm{~d}$ consumed on average more squid in the day (body length $=20.6 \pm 0.9 \mathrm{~mm}$; meal size $=6.6 \pm 2.6 \mathrm{mg}$ dry weight, $11.1 \pm 5.0 \%$ of net dry body weight; $n=11$ ) than at night (body length $=20.8 \pm 0.7 \mathrm{~mm}$; meal size $=5.1 \pm 3.4 \mathrm{mg}$ dry weight, $8.1 \pm 5.6 \%$ of net dry body weight; $n=8$ ), but differences were not significant (Mann-Whitney U-test, $p>0.05)$. Numbers of males were insufficient for comparisons; one male fed in the day consumed $3.3 \mathrm{mg}$ dry weight $(7.1 \%$ of net dry body weight), while the 6 males fed at night consumed on average $3.6 \pm 2.3 \mathrm{mg}$ dry weight $(9.5 \pm 6.6 \%$ of net dry body weight). Endogenous rhythms, if any, and the low levels of light during the experiments, apparently had no effect on the feeding response.

Partial correlations between 5 experimental variables (body length, net dry body weight, time spent feeding, absolute meal size, duration of starvation) are presented in Table 2. Feeding rate was excluded from the partial correlation matrix because it is the quotient of meal size and time spent feeding. Of the significant partial correlations obtained for females, one was trivial (body length with body weight), and 4 were important. Meal size was positively correlated with body length, with time spent feeding and with duration of starvation, but negatively correlated with net dry body weight. In the less abundant male group, meal size was positively and significantly correlated with duration of starvation and with time spent feeding. There was no significant correlation between duration of starvation and feeding rate of females (Spearman coefficient of rank correlation, $\left.r_{s}=0.15, p>0.05, n=109\right)$ and males $\left(r_{s}=0.38\right.$, $\mathrm{p}>0.05, \mathrm{n}=13$ )

Scatterplots and regression equations of the quantity of squid consumed versus the time spent feeding by females and males appear in Fig. 2 and Table 3, respectively. Small negative values of meal size were occasionally encountered, for individuals starved up to $3 \mathrm{~d}$, because of the variability inherent in the squid correction factors. In the case of females, the points appear to be distributed in a slightly non-linear manner, and significance of the regression may be improved by a 
square root or log transformation of time spent feeding. However, there is no reason to believe that the relation is non-linear.

The increase in average meal size, expressed in Fig. 3 as a proportion of net dry body weight of females and males, was gradual over the first 15 d of starvation. Thereafter, absolute and relative food consumption stabilized. The decline in relative meal size of females starved for $25 \mathrm{~d}$ was probably due to their poor health condition. Coefficients of variation (CV) of the meal size of females were negatively correlated with the duration of starvation $\left(\mathrm{r}_{\mathrm{s}}=-0.94, \mathrm{p}<0.01, \mathrm{n}=12\right)$ : the coefficient ranged between 79 and $262 \%$ for females starved up to $4 \mathrm{~d}$, but only between 33 and $59 \%$ for females starved 15 to $30 \mathrm{~d}$.

Because absolute meal size was maximum, most normally distributed, and least variable for individuals starved 15 to $30 \mathrm{~d}$, only data for this period were used to determine average meal size, satiation time and feeding rate (Table 4). Predicted meal size, derived from a regression of gut volume on body length (Sainte-Marie 1984), is also presented in Table 4. Absolute meal size of females was less than that of males. The largest meal, $16.4 \mathrm{mg}$ dry weight, was ingested by a female with poorly developed gonads. Relative meal size of males was almost twice as great as that of females, because of greater absolute meal size and lesser body weight. Apparently, females satiated faster than males and had a higher feeding rate. Statistical comparisons were not performed between sexes because of the small number of males and of differences in mean body length.

During a study of the effect of starvation on Anonyx nugax (Phipps) (Sainte-Marie \& Percy unpubl.), a few second year class A. sarsi were inadvertently starved for up to $30 \mathrm{~d}$ according to the experimental protocol described herein. These were collected in February 1987 in the vicinity of the Mingan Archipelogo (Lat. $50^{\circ} 13^{\prime} 00^{\prime \prime} \mathrm{N}$, Long. $\left.63^{\circ} 39^{\prime} 45^{\prime \prime}\right)$, Gulf of St. Law- rence. They too showed an incipient trend of increasing meal size over the first $15 \mathrm{~d}$ of starvation, followed by a plateau in meal size. The morphometric and feeding parameters of individuals starved 15 to $30 \mathrm{~d}$ are presented in Table 5. Males were sexually mature, and females were nearly mature $(n=2)$, mature but not yet berried ( $n=3$ ), or berried ( $n=1$ ). The berried female (22 $\mathrm{mm}$ in length) consumed only $3 \mathrm{mg}$ dry weight of

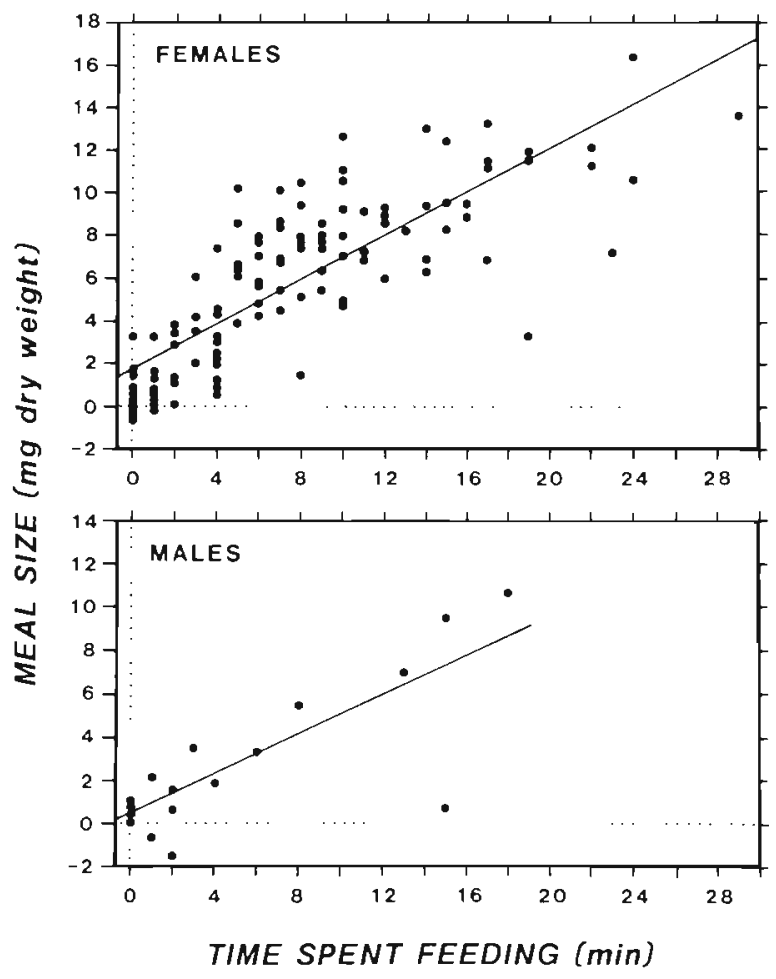

Fig. 2. Anonyx sarsi from Bale des Rochers. Scatterplot and predictive regression line of absolute meal size on time spent feeding for females and males starved 1 to $30 \mathrm{~d}$. One female which ingested $6.85 \mathrm{mg}$ of dry squid in $55 \mathrm{~min}$ was excluded from scatterplot. Equations of functional and predictive regressions appear in Table 3

Table 3. Anonyx sarsi. Equations of functional (F) and predictive (P) regressions of absolute meal size (M, mg dry weight) on time spent feeding $(T, m i n)$ of individuals starved 1 to $30 \mathrm{~d}$. $\mathrm{n}$ : sample size; $\mathrm{I}$ : correlation coefficient; $\mathrm{r}^{2}$ : coefficient of determination; $\mathrm{F}$ : F-ratio of the regression. Regression coefficients are highly significant $(p<0.001)$

\begin{tabular}{|c|c|c|c|c|c|}
\hline & Equation of regression & $\mathrm{n}$ & r & $r^{2}$ & $\mathrm{~F}$ \\
\hline \multicolumn{6}{|c|}{ Baie des Rochers } \\
\hline Females & $\begin{array}{l}(F): M=0.63 T+0.93 \\
(P): M=0.52 T+1.69\end{array}$ & $\begin{array}{l}130 \\
130\end{array}$ & 0.83 & 0.69 & 279 \\
\hline Males & $\begin{array}{l}(F): M=0.55 T-0.07 \\
\text { (P): } M=0.45 T+0.41\end{array}$ & $\begin{array}{l}20 \\
20\end{array}$ & 0.81 & 0.66 & 34 \\
\hline \multicolumn{6}{|c|}{ Baie des Rochers and Mingan Archipelago, combined } \\
\hline Males & $\begin{array}{l}(F): M=0.61 T+0.46 \\
(P): M=0.51 T+1.12\end{array}$ & $\begin{array}{l}47 \\
47\end{array}$ & 0.79 & 0.62 & 47 \\
\hline
\end{tabular}


squid, equivalent to $4.9 \%$ of net dry body weight. Absolute meal size of females, despite greater mean body length, was less than that of males. Relative meal size of females was less than half that of males. However, there was no apparent difference between mean feeding rate of females and males.

Meal size of non-berried females from Mingan was equal, despite greater mean length, to that of females from Baie des Rochers (Tables 4 \& 5). Mean feeding rates of both groups of females were similar. Mean body length of males from Mingan and Baie des Rochers was identical, and both groups were composed exclusively of sexually mature individuals. There was little disparity, and no significant difference (MannWhitney U-test, $p>0.05$ ), between absolute or relative meal size of males from Baie des Rochers and the Mingan Archipelago (Tables 4 \& 5). Mean feeding rate of Mingan males was greater, but not significantly so $(p>0.05)$, than that of Baie des Rochers males. Better functional and predictive regressions of meal size on time spent feeding may be obtained for males by pooling data for individuals from both environments (Table 3).

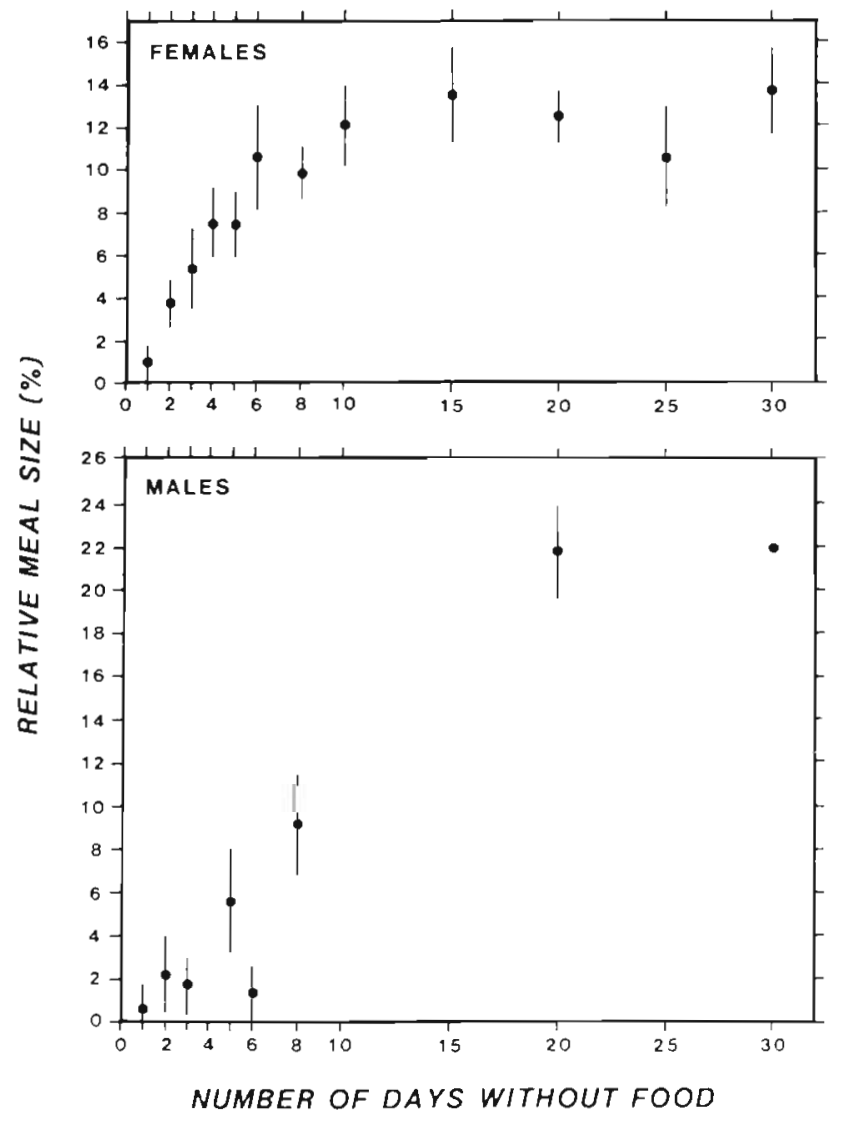

Fig. 3. Anonyx sarsi from Baie des Rochers. Mean relative size ( $\%$ of net dry body weight), \pm 1 standard error of mean, of meals ingested by females and males as a function of the duration of starvation

\section{DISCUSSION}

Average meal size of Anonyx sarsi increased gradually with duration of starvation, until maximum ingestion occurred in healthy individuals at $\geq 15$ d of starvation (Fig. 3). Over the same period, egestion peaked, decreased, and ceased completely. Fifteen $d$ was the maximum amount of time required by $A$. sarsi to digest and egest a meal of squid under the present experimental conditions.

It is unlikely that all the Anonyx sarsi used in the experiment followed the same feeding pattern during or before the $10 \mathrm{~d}$ preparatory phase which preceded isolation and starvation. The coefficient of variation of meal size decreased as duration of starvation increased, indicating that individual differences in feeding readiness existed at the onset of the experiment, and that they could be greatly reduced by prolonged starvation. The response of various scavenger and predator species to novel feeding conditions may depend on the frequency and nature of meals experienced in the past (e. g. Wood 1968, Mackie 1973, Present \& Smith 1981, McClintock \& Lawrence 1984). The present experiment shows that at least $15 \mathrm{~d}$ of starvation are required to standardize feeding readiness of $A$. sarsi.

Because short-term feeding histories were not properly standardized before experimentation, individual feeding responses could differ markedly from the gradual response depicted in Fig. 3. More than $50 \%$ of individuals did not feed, or fed very little, following the first $6 \mathrm{~d}$ of starvation (Fig. 1). A plot of the mode of meal size, in lieu of the mean, would produce a sigmoidal curve in Fig. 3. It may well be that a meal is followed by a period of repose, during which Anonyx sarsi is not responsive to food. For instance, changes in chemosensory thresholds, related to the nutritional condition of individuals, could intervene. Feeding to satiety has been shown to depress swimming (i. e. food searching) activity of the herbivorous amphipod Marinogamarus obtusatus Dahl (Mackintosh 1973).

Meal size depends in part on body length (Table 2 and Sainte-Miarie 1984). Meal size is also limited by the rigid dorsal and lateral body walls, and to a lesser extent by the ventral integument, which do not conspicuously expand while Anonyx sarsi is feeding (Sainte-Marie 1984) This is unlike the situation in some deep-sea lysianassid species, in which feeding may cause djlation and distortion of body walls (Shulenberger \& Hessler 1974, Dahl 1979, Thurston 1979). Residence (digestion) time of food in the foreand midgut, where it is stored (Sainte-Marie 1984), would also affect capacity to ingest food. Until food from the penultimate meal is digested and shunted to the hindgut, a full meal cannot be ingested. 
Table 4. Anonyx sarsi from Baie des Rochers. Absolute (mg dry weight) and relative (\% of net dry body weight) meal size, satiation time (min), feeding rate ( $\mathrm{mg}$ dry weight $\mathrm{min}^{-1}$ ) and body length ( $\mathrm{mm}$ ) of females and males starved for 15 to $30 \mathrm{~d}$, excluding diseased and recently moulted individuals. Maxima are from the 15 to 30 d period unless specified otherwise. Predicted meal size was derived for mean body length $(\mathrm{mm})$ by using predicted gut volume $\left(\mathrm{mm}^{3}\right)$ and equations for density of squid bait provided in Table 1 , assuming $1 \mathrm{~mm}^{3}=10^{-3} \mathrm{~mL}$ of bait. Numbers in parentheses are fresh weight equivalents obtained from regression in Table 1

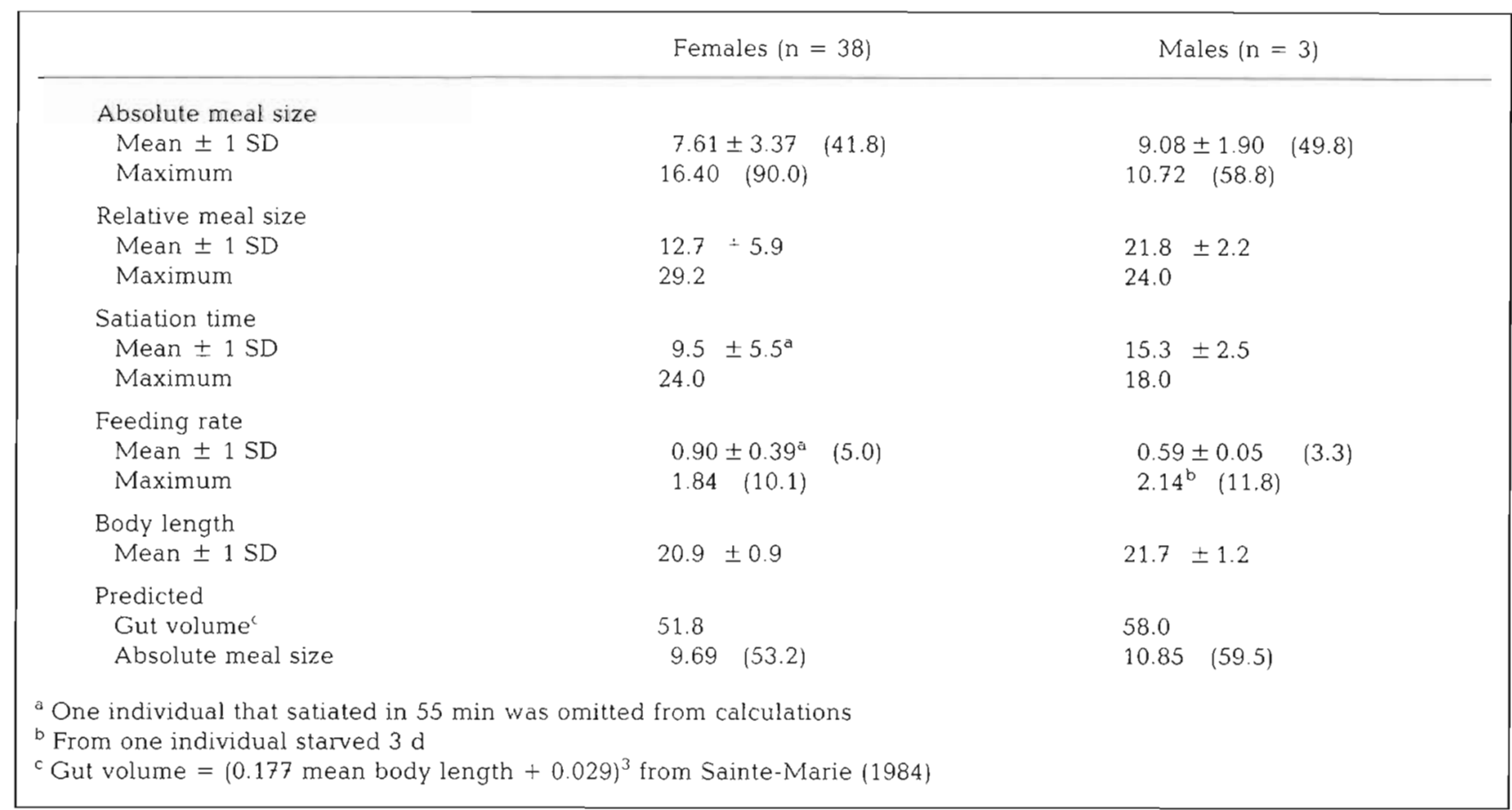

Table 5. Anonyx sarsi from Mingan Archipelago. Absolute (mg dry weight) and relative (\% of net dry body weight) meal size, satiation time (min), feeding rate ( $\mathrm{mg}$ dry weight $\mathrm{min}^{-1}$ ) and body length ( $\mathrm{mm}$ ) of females and males starved for 15 to $30 \mathrm{~d}$, excluding diseased and recently moulted individuals. Predicted meal size was derived for mean body length (mm) by using predicted gut volume $\left(\mathrm{mm}^{3}\right)$ and equations for density of squid bait provided in Table 1 , assuming $1 \mathrm{~mm}^{3}=10^{-3} \mathrm{ml}$ of bait. Numbers in parentheses are fresh weight equivalents obtained from regression in Table 1

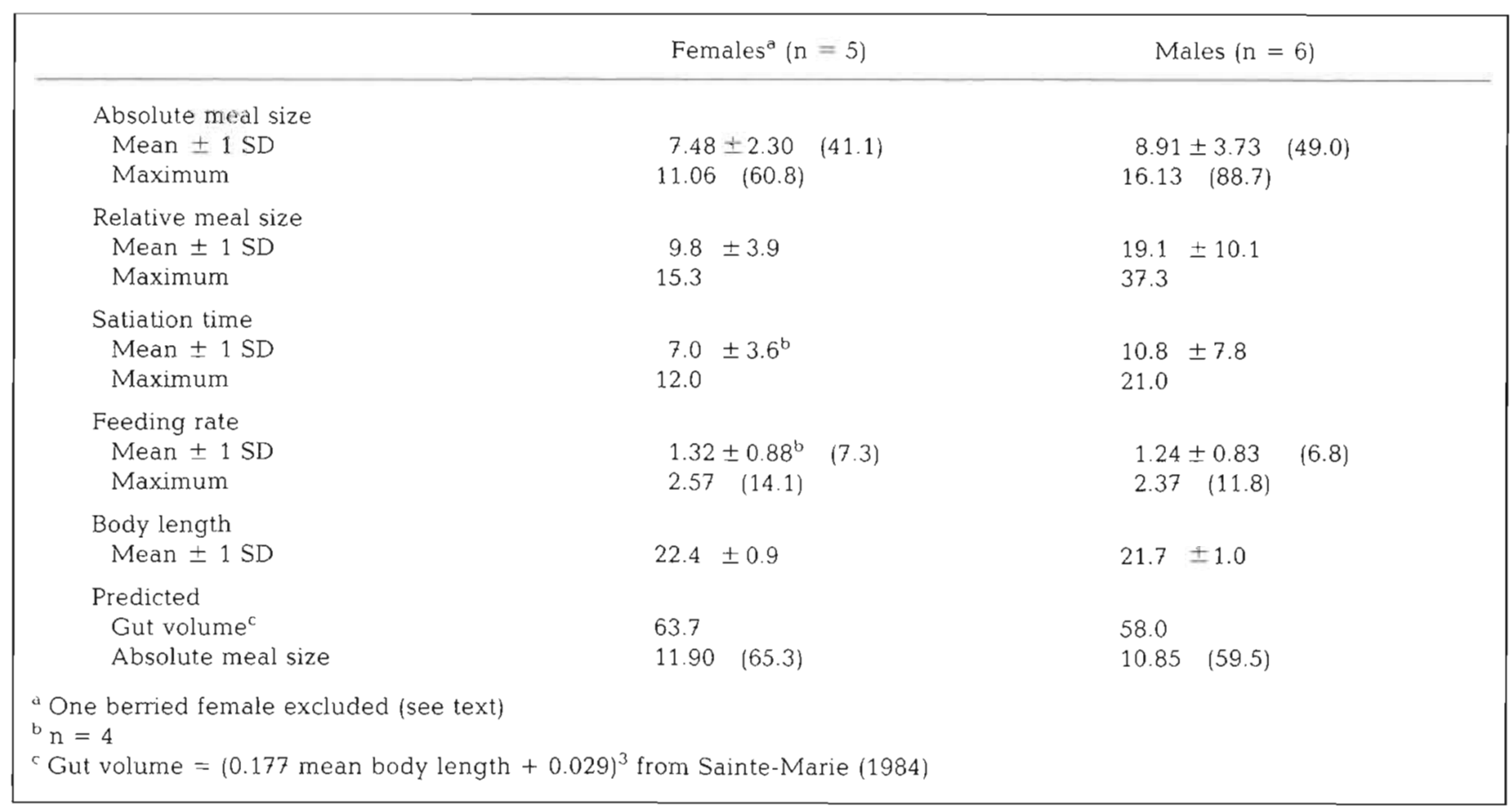


Sex and degree of maturity also affect meal size of Anonyx sarsi. Differences between predicted and observed absolute meal size (Tables $4 \& 5$ ) were greater in females (Baie des Rochers, $+27 \%$; Mingan, +59\%) than in males (Baie des Rochers, $+19 \%$; Mingan, $+22 \%$ ). The maturing oocytes, which numbered 60 to 120 and each occupied approximately 0.5 to $1 \mathrm{~mm}^{3}$ in volume, probably constricted the fore- and midgut, decreasing their capacity to hold food. The fact that the discrepancy between predicted and observed meal size was greater among the more mature females from Mingan is additional proof for this assertion. Also, the significant negative partial correlation between meal size and body weight of females indicated that heavier females (i. e. with larger gonads) ate less squid than lighter females, for a same body length. However, there is an alternative or complementary explanation for the negative partial correlation of meal size with body weight. Individuals laden with food and/or lipids may not be able to ingest, or inclined to feed, as much as those with empty guts or small lipid reserves. This explanation would account for the relatively strong, albeit non-significant, partial correlation between meal size and body weight of males (Table 2).

The decrease of relative meal size with increasing maturity of females, due to the combined effects of gut constriction and increased body weight caused by the developing gonads, may not hold true for deep-sea lysianassids with expansive body walls. Eventually however, most females of semeiparous, shallow-water or deep-sea lysianassid species, including Anonyx sarsi, stop feeding on bait or carrion before or shortly after they begin brooding (Bregazzi 1972, Hessler et al. 1978, Thurston 1979, Sainte-Marie \& Lamarche 1985). The physiological basis for the cessation of flesh-feeding is unknown.

Regardless of sex, predicted absolute meal size of Anonyx sarsi was greater than observed absolute meal size (Tables 4 \& 5). Predicted absolute meal size was probably biased toward higher values because I deliberately selected satiated individuals (Sainte-Marie 1984). Also, observed meal sizes were probably slightly underestimated, for reasons explained in 'Materials and Methods'.

Meal size was positively correlated with time spent feeding (Table 3, Fig. 2). Time spent feeding can thus be used to estimate meal size, as assumed by Hargrave (1985), if specimens are uniform in body size. Indeed, it seems likely that the feeding rate will prove to be sizedependent, when a broader range of body sizes is examined. Caution is also needed because of the occasional difficulty in determining whether individuals on food were actually feeding. There was aparently no difference between feeding rates of females and males, considering the range of observed values recorded for individuals from Baie des Rochers and the Mingan Archipelago (Tables 3, 4 \& 5).

There is little information on the feeding rates and meal sizes of lysianassids. Sainte-Marie (1984, 1986c) concluded that relative meal size of Anonyx sarsi, which belongs to a genus of presumably specialized carrion feeders, would exceed that of other shallowwater lysianassids. Present \& Smith's (1981) data for Orchomene limodes are not comparable with mine, because they measured consumption of oven-dried squid over a $24 \mathrm{~h}$ period, during which individuals ingested several meals. The mean feeding rate of $A$. sarsi, 3 to $7 \mathrm{mg}$ fresh weight $\mathrm{min}^{-1}$, was 4 to 10 times less than the $1.8 \mathrm{~g} \mathrm{~h}^{-1}$ reported by Hargrave (1985) for the large abyssal Eurythenes gryllus. Direct comparison between meal size of $A$. sarsi and of E. gryllus is not possible because of differences in body size. However, Hargrave (1985) estimated that E. gryllus could consume between 30 and $60 \%$ of its equivalent fresh body weight in one meal, while the present study shows that A. sarsi does not consume more than $37 \%$ of its equivalent net dry body weight (or net fresh body weight, if squid and lysianassid have the same water content). Such a difference was expected, since carrion is thought to be a much scarcer resource in the deep sea than in most shallow-water environments. Deep-sea necrophagous animals must therefore secure larger amounts of carrion when it becomes available (Dahl 1979).

Acknowledgements. I thank J. A. Percy, F. J. Fife, P. N. Riebel and J. R. Shea for their suggestions and/or help in the laboratory. They, B.T Hargrave, and 4 anonymous reviewers helped improve the manuscript. I was supported during this work by a postdoctoral fellowship from the Québec Ministry of Education (FCAR).

\section{LITERATURE CITED}

Arnaud, P. M. (1970). Frequency and ecological significance of necrophagy among the benthic species of the Antarctic coastal waters. In: Holdgate, M. W. (ed.) Antarctic ecology, Vol. 1. Academic Press. New York, p. 259-267

Arnaud, P. M (1977). Adaptations within the Antarctic marine benthic ecosystem. In: Llano, G. A. (ed.) Adaptations within the Antarctic marine benthic ecosystem. Proceedings of the 3rd Symposium on Antarctic biology. Smithsonian Institution, Washington, p. 135-157

Bregazzi, P. K. (1972). Life cycles and seasonal movements of Cheirimedon femoratus (Pfeffer) and Tryphosella kergueleni (Miers) (Crustacea: Amphipoda). Br. Antarct. Sury. Bull. 30: 1-34

Dahl, E. (1979). Deep-sea carrion feecling amphipods evolutionary patterns in niche adaptation. Oikos 33 $167-175$

Dayton, P. K., Hessler, R. R. (1972). Role of biological disturbance in maintaining diversity in the deep sea. Deep Sea Res. 19: 199-208 
Hargrave, B. T (1985). Feeding rates of abyssal scavenging amphipods (Eurythenes gryllus) determined in situ by time-lapse photography. Deep Sea Res. 32: 443-450

Hessler, R. R., Ingram, C. L., Yayanos, A. A., Burnett, B. R. (1978). Scavenging amphipods from the floor of the Philippine Trench. Deep Sea Res. 25: 1029-1047

Ingram, C. L., Hessler, R. R. (1983). Distribution and behavior of scavenging amphipods from the central North Pacific. Deep Sea Res. 30: 683-706

Mackie, A. M. (1973). The chemical basis of food detection in the lobster Homarus gammarus. Mar. Biol. 21: 103-108

Mackintosh, J. (1973). The effect of hunger and satiety on swimming activity in the amphipod, Marinogammarus otusatus Dahl. Comp. Biochem. Physiol, 45A: 483-487

McClintock, J. B., Lawrence, J. M. (1984). Ingestive conditioning in Luidia clathrata (Say) (Echinodermata: Asteroidea): effect of nutritonal condition on selectivity, teloreception, and rates of ingestion. Mar. Behav. Physiol. 10: 167-181

Meador, J. P. (1981). Chemoreception and food-finding abilities of a lysianassid amphipod. M. Sc. thesis, San Diego State University, San Diego

Present, T M. C., Smith, C. R. (1981). Feeding activity and energetics in Orchomene n.sp.. project summary. In: Hinga, K. R. (ed.) Subseabed disposal program annual report, January to September 1981, No. 2. Sandia National Laboratories, Albuquerque, p. 535-558

Ricker, W. E. (1973). Linear regression in fishery research. J. Fish. Res. Bd Can. 30: 409-434

Rowe, G. T., Sibuet, M., Vangriesheim, A. (1986). Domains of occupation of abyssal scavengers inferred from baited cameras and traps on the Demerara Abyssal Plain. Deep Sea Res. 33: 501-522

Rowe, G. T., Staresinic, N. (1979). Sources of organic matter to the deep-sea benthos. Ambio Spec. Rep. 6: 19-23

Sainte-Marie, B. (1984). Morphological adaptations for carrion feeding in four species of littoral or circalittoral lysianassid amphipods. Can. J. Zool. 62: 1668-1674
Sainte-Marie, B. (1986a). Foraging by lysianassid amphipods. Ph. D. thesis. Dalhousie University, Halifax

Sainte-Marie, B. (1986b). Feeding and swimming of lysianassid amphipods in a shallow cold-water bay. Mar. Biol. 91·219-229

Sainte-Marie, B. (1986c). Effect of bait size and sampling time on the attraction of the lysianassid amphipods Anonyx sarsi Steele \& Brunel and Orchomenella pinguis (Boeck). J. exp. mar. Biol. Ecol. 99: 63-77

Sainte-Marie, B., Hargrave, B. T. (1987). Estimation of scavenger abundance and distance of attraction to bait. Mar. Biol. 94: 431-443

Sainte-Marie, B., Lamarche, G. (1985). The diets of six species of the carrion-feeding lysianassid amphipod genus Anonyx and their relation with morphology and swimming behavior. Sarsia 70: 119-126

Shulenberger, E., Hessler, R. R. (1974). Scavenging abyssal benthic amphipods trapped under oligotrophic central north Pacific gyre waters. Mar. Biol. 28: 185-187

Slattery, P. N., Oliver, J. S. (1986). Scavenging and other feeding habits of lysianassid amphipods (Orchomene spp.) from McMurdo Sound, Antarctica. Polar Biol. 6: 171-177

Smith, C. R. (1985). Food for the deep sea: utilization, dispersal, and flux of nekton falls at the Santa Catalina Basin floor. Deep Sea Res. 32: 417-442

Smith, K. L., J5., Baldwin, R. J. (1982). Scavenging deep-sea amphipods: effects of food odor on oxygen consumption and a proposed metabolic strategy. Mar. Biol. 68: 287-298

Sokal, R. R., Rohlf, F. J. (1981). Biometry. W. H. Freeman, New York

Stockton, W. L., DeLaca, T E. (1982). Food falls in the deep sea: occurrence, quality, and significance. Deep Sea Res. 29: $157-169$

Thurston, M. H. (1979). Scavenging abyssal amphipods from the northeast Atlantic Ocean. Mar Biol. 51: 55-68

Wood, L. (1968). Physiological and ecological aspects of prey selection by the marine gastropod Urosalpinx cinera (Prosobranchia: Muricidae). Malacologia 6: 167-320

This article was presented by Dr R. R. Hessler; it was accepted for printing on July 31, 1987 